\title{
CONSTITUCIONALISMO ESTADUAL E CONTROLE ABSTRATO E CONCENTRADO DE CONSTITUCIONALIDADE NOS TRIBUNAIS DE JUSTIÇA: EFEITOS DAS AÇÕES DIRETAS DE INCONSTITUCIONALIDADE (ADI) ESTADUAIS NA FEDERAÇÃO BRASILEIRA
}

\author{
STATE CONSTITUTIONALISM AND ABSTRACT AND CONCENTRATED JUDICIAL REVIEW IN \\ STATE APPELLATE COURTS: EFFECTS OF STATE DIRECT STATE ACTION OF \\ UNCONSTITIONALITY (ADI) IN THE BRAZILIAN FEDERATION
}

Fabricio Ricardo de Limas Tomio

Doutor em Ciência Política - UNICAMP. Professor Associado de Teoria do Estado e Ciência Política da Faculdade de Direito - UFPR. Email: fab_tom@ hotmail.com

Ilton Norberto Robl Filho

Doutor em Direito - UFPR. Filiação Institucional: Professor Adjunto da Faculdade de Direito da UFPR e Professor da Universidade de Passo Fundo (UPF). Email: norbertorobl@gmail.com

\section{Rodrigo Luis Kanayama}

Doutor em Direito - UFPR; Professor Adjunto da Faculdade de Direito - UFPR. Email: rodrigokanayama@icloud.com

\section{Resumo}

O conceito de federação remete a existência de pelo menos dois centros de competência. O conflito entre entes federativos aparece de forma clara no exercício do controle abstrato de constitucionalidade. No Brasil, o árbitro em conflitos federativos entre união e estados-membros é o Supremo Tribunal Federal (STF). O principal mecanismo pelo qual essas disputas ocorrem atualmente é a ação direta de inconstitucionalidade (ADI). A Constituição Federal (CF) previu a possibilidade desse controle para atos normativos estaduais e municipais em face da Constituição Estadual ser realizado pelos Tribunais de Justiça (TJs). O objetivo deste artigo é verificar se o papel exercido pelos TJs promove a centralização do poder político e jurídico, verificando as hipóteses de que esse controle: a) torna os TJs atores relevantes no processo decisório subnacional; b) é mais forte em relação aos atos normativos municipais; c) concentra-se na declaração de normas inconstitucionais por vícios formais; d) produz efeitos na relação entre Executivo e Legislativo municipais. O levantamento de dados da jurisprudência das ADIs estaduais (20 mil ADIs em 26 TJs) aponta que: esse controle é efetivo (dezenas de milhares de normas nulificadas); direciona-se às normas municipais $(93 \%)$; principalmente por vícios formais $(70 \%)$; o tipo mais frequente de 
ADI procedente envolve um Prefeito requerendo a anulação de legislação da Câmara arguindo vício de iniciativa.

Palavras-Chave: Judicialização da Política. Processo Decisório. Instituições Políticas. Controle Concentrado/Abstrato de Constitucionalidade. Jurisdição Constitucional.

\begin{abstract}
The concept of federation supposes the existence of at least two centers of competences (power). The conflict between federative bodies is clearly demonstrated in the exercise of abstract judicial review. In Brazil the arbiter of federative conflicts between the union and member-states is the Supreme Federal Court (STF). The main mechanism by which these disputes currently occur is the Direct Action of Unconstitutionality (ADI). The Federal Constitution allowed for the possibility of this type of review over state and municipal normative acts in conflict with the state constitution, decided by the state appellate courts (TJs). This paper seeks to analyze if the role played by the state appellate courts promotes the centralization of political and legal powers, testing the hypothesis that this control: a) makes the TJs relevant agents in the sub-national decision-making process; b) is stronger in relation to municipal normative acts; c) is concentrated in the declaration of norms unconstitutional due to formal vices; d) affects the relation between municipal state and executive branches. The compiling of data and legal cases of State Direct Action of Unconstitutionality $(20,000$ ADIs in 26 TJs) denotes that: this review is effective (tens of thousands norms nullified); it is directed to municipal norms (93\%); primarily due to formal vices (70\%); the most frequent type of successful ADIs involves a Mayor seeking the annulment of City Council legislation due to vice of initiative.
\end{abstract}

Key-words: Judicializing politics. Decision-making process. Political institutions. Abstract/Concentrated judicial review. Constitutional jurisdiction.

\title{
INTRODUÇÃO
}

O presente artigo discute o efeito das Ações Diretas de Inconstitucionalidade (ADIs) Estaduais propostas contra atos normativos estaduais e municipais. A primeira seção do texto apresenta as relações entre federalismo e controle judicial concentrado e abstrato de constitucionalidade, demonstrando que as ADI ajuizadas no STF promovem o aumento da centralização federativa.

A segunda seção do artigo reflete sobre a estrutura do federalismo brasileiro em perspectiva comparada no tempo (Constituições brasileiras republicanas). Posteriormente, os 
autores enfrentam a discussão sobre o constitucionalismo estadual e a autonomia municipal brasileira.

O tema do controle judicial de constitucionalidade estadual, as hipóteses acerca do efeito desse controle na Federação brasileira e a descrição, análise e interpretação dos dados de 19.196 ADI estaduais julgadas entre 1990 e 2013 são tratadas na quarta seção. Por fim, são apresentadas breves considerações finais.

\section{CONSTITUCIONALISMO, FEDERAÇÃO E JUDICIÁRIO: O IMPACTO DAS ADIS NO STF SOBRE A INSTITUCIONALIDADE FEDERATIVA BRASILEIRA}

O constitucionalismo contemporâneo relaciona-se de maneira umbilical e intensa com o fenômeno do Federalismo. A primeira constituição escrita, forjada nos Estados Unidos da América, foi criada para distribuir as competências entre a União (governo central) e os Estados-membros.

Em razão da autonomia concedida aos estados membros nas Federações, surge o fenômeno do constitucionalismo estadual, que consiste na configuração dos poderes estatais estaduais e no estabelecimento de direitos fundamentais e humanos a partir de constituições dos estados-membros. Há pequena bibliografia sobre a relevância e o impacto das constituições estaduais nas instituições jurídicas, políticas e sociais nas federações contemporâneas ${ }^{1}$. Mesmo nos Estados Unidos, federação com considerável descentralização dos poderes administrativos e legislativos para os entes subnacionais, o estudo universitário sobre as constituições estaduais recebe diminuta importância (LEVINSON, 2014, p. 581$582)$.

De outro lado, reconhece-se o papel do judiciário como o árbitro por excelência do conflito entre os entes federativos ${ }^{2}$, mas, novamente, a literatura é escassa sobre essa relação. Em verdade, a literatura contemporânea, principalmente no âmbito jurídico, discute a relevância da jurisdição e principalmente da jurisdição constitucional (controle judicial de constitucionalidade) na garantia dos direitos. ${ }^{3}$

\footnotetext{
${ }^{1}$ Para uma apresentação bibliografia sobre o constitucionalismo estadual em algumas federações atuais, cf. Willians (2011, p. 1113-115). Sobre os estudos acerca do constitucionalismo estadual nos Estados Unidos, cf. Barr (1995).

${ }^{2}$ Nesse sentido, cf. Hamilton; Madison; Jay (2009, p. 489-494) e Canotilho (2003, p. 892-894).

${ }^{3}$ A Ciência Política brasileira acumulou na última década um conhecimento descritivo e, eventualmente, analítico sobre a participação do STF no processo decisório, através do estudo dos julgamentos de milhares de 
Nesse sentido são os estudos e reflexões de Dworkin (2006, p. 2-3), que afirma a necessidade de os magistrados concretizarem os princípios morais e jurídicos centrais postos na Constituição, sendo esses princípios as fontes dos direitos fundamentais. ${ }^{4}$ Discussões e debates teóricos sobre o papel e a função de órgãos contramajoritários na garantia de direitos individuais e coletivos representa o cerne dos temas constitucionais estudados ${ }^{5}$.

O controle judicial de constitucionalidade no Brasil, em razão do seu caráter difuso (análise por qualquer magistrado ou tribunal no caso concreto da observância da constituição estadual e federal) e concentrado da constituição federal pelo Supremo Tribunal Federal (STF) e das constituições estaduais pelos tribunais de justiça $(\mathrm{TJ} s)^{6}$, possui papel central na construção de interpretações e decisões sobre temas políticos e constitucionais.

Recentemente, Tomio e Robl (2013) buscaram mensurar o impacto das Ações Diretas de Constitucionalidade (ADI) julgadas no STF no período de 1988 a 2012 sobre a garantia dos direitos e o pacto federativo. O principal resultado dessa pesquisa empírica apontou que, de um lado, essas ações produzem a centralização do poder normativo na União e, de outro lado, há pequena quantidade de ADIs exitosas na proteção e promoção dos direitos

ADI em variados aspectos (VIANNA, BURGOS e SALLES, 2007; CARVALHO, 2009; TAYLOR e DA ROS, 2008; TOMIO e ROBL, 2013). Também são encontrados estudos comparados sobre o padrão decisório dos Tribunais Constitucionais em judicial review (BZDERA, 1993; VANBERG, 1998; FIGUEROA e TAYLOR, 2006; AILIVIZATOS, 1995). Entretanto, são escassos os estudos que comparam o STF e Tribunais Constitucionais Estaduais com controle abstrato/concentrado de constitucionalidade no processo decisório e nas competências federativas, buscando dimensionar e explicar a judicialização da política brasileira em uma perspectiva empírica e comparada.

${ }^{4}$ Observam-se relevantes juristas de países em que ocorreu o processo de redemocratização nas décadas de setenta e oitenta do século passado defendendo o judicial review a partir da sua importância na garantia de direitos individuais e de grupos, cf. Gargarella (2008, p. 827-837) na Argentina, Canotilho (2003, p. 682) em Portugal e Clève (2001, p. 54-60) no Brasil. Inegavelmente a garantia dos direitos é elemento essencial na consolidação das democracias constitucionais.

${ }_{6}^{5}$ Nesse mesmo sentido, cf. Levinson (2014, p. 581).

${ }^{6} \mathrm{O}$ controle abstrato não possui partes, nem serve, a priori, à proteção de direito subjetivo. Não é processo judicial interpartes, com pretensões opostas, e não se refere a caso concreto, a materialidade da aplicação da norma, à subsunção de fatos à norma. Aqui, o processo aprecia a adequação do texto abstrato da lei ou ato normativo ao texto constitucional. No Brasil, como precursora do controle abstrato surge a representação interventiva, debatida na Constituinte de 1891 como "possibilidade de outorgar ao Supremo Tribunal Federal a competência para conhecer de alegação de ofensa pelo Estado-Membro a determinados princípios da ordem federativa" (MENDES, G., 2014, p. 89), sendo positivada na Constituição de 1934. Pela Emenda Constitucional 16 de 1965, foi acrescentado, junto à representação interventiva e "segundo seu modelo, um sistema de controle abstrato de normas perante o Supremo Tribunal Federal, destinado à aferição da constitucionalidade das leis ou atos normativos federais ou estaduais" (MENDES, G., 2014, p. 93), processo que poderia ser instaurado por requerimento do Procurador-Geral da República (art. 101, 1, k). Por sua vez, sob a Constituição de 1988, o número de legitimados para propositura de ação direta de inconstitucionalidade foi ampliado, reduzindo de certa forma o controle incidental ou difuso. No texto constitucional (art. 103), podem propor Ação Direta diversos atores - Presidente da República, a Mesa do Senado Federal, a Mesa da Câmara dos Deputados, a Mesa da Assembleia Legislativa ou Câmara Legislativa do Distrito Federal, Governador de Estado ou Distrito Federal, Procurador-Geral da República, Conselho Federal da OAB, partido político com representação no Congresso Nacional - contrariando regime pretérito. 
fundamentais. Essa centralização ocorre em razão da razoável taxa de declaração de atos normativos estaduais pelo STF e pela pequena quantidade de reconhecimento de inconstitucionalidades dos atos federais/nacionais, conforme se observa na Tabela 1.

TABELA 1 - Controle Concentrado de Constitucionalidade - ADI 1998-2013 - STF

\begin{tabular}{|c|c|c|c|c|c|c|c|c|c|c|}
\hline \multirow{3}{*}{ Decisão } & \multirow{3}{*}{\multicolumn{2}{|c|}{ Resultado ADI }} & \multicolumn{6}{|c|}{ Processo Decisório Judicializado (STF) } & \multirow{2}{*}{\multicolumn{2}{|c|}{ TOTAL }} \\
\hline & & & \multicolumn{2}{|c|}{ FEDERAL } & \multicolumn{2}{|c|}{ ESTADUAL } & \multicolumn{2}{|c|}{ MUNICIPAL } & & \\
\hline & & & $\mathrm{N}$ & $\%$ & $\mathrm{~N}$ & $\%$ & $\mathrm{n}$ & $\%$ & $\mathrm{n}$ & $\%$ \\
\hline \multirow{11}{*}{ Final } & \multirow{2}{*}{ Procedente } & $\mathrm{N}$ & 96 & $12 \%$ & 687 & \multirow{2}{*}{\multicolumn{3}{|c|}{$88 \%$}} & 783 & \multirow[t]{2}{*}{$100 \%$} \\
\hline & & $\%$ & $5 \%$ & & $22 \%$ & & & & $16 \%$ & \\
\hline & \multirow{2}{*}{$\begin{array}{l}\text { Procedente em } \\
\text { Parte }\end{array}$} & $\mathrm{n}$ & 48 & $22 \%$ & 174 & \multirow{2}{*}{\multicolumn{3}{|c|}{$78 \%$}} & 222 & \multirow[t]{2}{*}{$100 \%$} \\
\hline & & $\%$ & $3 \%$ & & $6 \%$ & & & & $4 \%$ & \\
\hline & \multirow{2}{*}{ Improcedente } & $\mathrm{n}$ & 95 & $46 \%$ & 113 & \multirow{2}{*}{\multicolumn{3}{|c|}{$54 \%$}} & 208 & \multirow[t]{2}{*}{$100 \%$} \\
\hline & & $\%$ & $5 \%$ & & $4 \%$ & & & & $4 \%$ & \\
\hline & \multirow{2}{*}{ Prejudicada } & $\mathrm{n}$ & 37 & $34 \%$ & 72 & \multirow{2}{*}{\multicolumn{3}{|c|}{$66 \%$}} & 109 & \multirow[t]{2}{*}{$100 \%$} \\
\hline & & $\%$ & $2 \%$ & & $2 \%$ & & & & $2 \%$ & \\
\hline & \multirow{2}{*}{ Não Conhecida } & $\mathrm{n}$ & 953 & $49 \%$ & 942 & \multirow[t]{2}{*}{$48 \%$} & 49 & \multirow[t]{2}{*}{$3 \%$} & 1.944 & \multirow[t]{2}{*}{$100 \%$} \\
\hline & & $\%$ & $53 \%$ & & $30 \%$ & & $100 \%$ & & $39 \%$ & \\
\hline & Total (Final) & $\begin{array}{l}\mathbf{n} \\
\%\end{array}$ & $\begin{array}{l}1.229 \\
68 \%\end{array}$ & $38 \%$ & $\begin{array}{l}1.988 \\
63 \%\end{array}$ & $61 \%$ & $\begin{array}{c}49 \\
100 \%\end{array}$ & $2 \%$ & $\begin{array}{l}3.266 \\
65 \%\end{array}$ & $100 \%$ \\
\hline \multirow{9}{*}{ Liminar } & \multirow{2}{*}{ Deferida } & $\mathrm{n}$ & 35 & $16 \%$ & 178 & \multirow[t]{2}{*}{$84 \%$} & & & 213 & \multirow[t]{2}{*}{$100 \%$} \\
\hline & & $\%$ & $2 \%$ & & $6 \%$ & & & & $4 \%$ & \\
\hline & & $\mathrm{n}$ & 23 & $37 \%$ & 39 & $63 \%$ & & & 62 & $100 \%$ \\
\hline & Defer & $\%$ & $1 \%$ & & $1 \%$ & & & & $1 \%$ & \\
\hline & & $\mathrm{n}$ & 50 & $46 \%$ & 59 & $54 \%$ & & & 109 & $100 \%$ \\
\hline & Indef & $\%$ & $3 \%$ & & $2 \%$ & & & & $2 \%$ & \\
\hline & & $\mathrm{n}$ & 9 & $60 \%$ & 6 & $40 \%$ & & & 15 & $100 \%$ \\
\hline & Prejudicada & $\%$ & $0 \%$ & & $0 \%$ & & & & $0 \%$ & \\
\hline & Total (Liminar) & $\begin{array}{l}\mathrm{n} \\
\%\end{array}$ & $\begin{array}{l}117 \\
6 \%\end{array}$ & $29 \%$ & $\begin{array}{l}282 \\
9 \%\end{array}$ & $71 \%$ & & & $\begin{array}{l}399 \\
8 \%\end{array}$ & $100 \%$ \\
\hline ADI Agu & ardando & $\mathbf{n}$ & 464 & $34 \%$ & 882 & $66 \%$ & & & 1.346 & $100 \%$ \\
\hline & & $\%$ & $26 \%$ & & $28 \%$ & & & & $27 \%$ & \\
\hline & TAL (ADI) & $\begin{array}{l}\mathbf{n} \\
\%\end{array}$ & $\begin{array}{l}1.810 \\
100 \%\end{array}$ & $36 \%$ & $\begin{array}{l}3.152 \\
100 \%\end{array}$ & $63 \%$ & $\begin{array}{c}49 \\
100 \%\end{array}$ & $1 \%$ & $\begin{array}{l}5.011 \\
100 \%\end{array}$ & $100 \%$ \\
\hline
\end{tabular}

Fonte: STF (ADI 1988-2013) - base de dados coletada e organizada pelo Núcleo de Pesquisa DIRPOL (Direito e Política) do PPGD/UFPR.

A Tabela 1 aponta que o processo decisório estadual é o mais presente no controle concentrado de constitucionalidade por meio de ADI no STF. Dois terços (63\%; 3.152 ADI) das 5.011 ADIs interpostas no STF, entre 1988 e 2013, tinham como objeto algum ato normativo do processo decisório estadual. Desses 3.152 atos normativos questionados no STF, a grande maioria (quase 90\%) constituía legislação aprovada pelas Assembleias Estaduais: 2.750 normas, sendo 800 emendas às Constituições Estaduais e 1.950 leis ordinárias e complementares estaduais. 
Para estimar o processo centralizador da jurisdição constitucional do STF, 402 ADIs contra emendas às cartas estaduais e 607 ações contra leis estaduais foram total ou parcialmente julgadas pró-requerentes (em decisão final e/ou liminar) pelo STF entre 1988 e 2013. ${ }^{7}$ Ainda, 35\% das ADIs direcionadas contra atos normativos estaduais foram julgadas pró-requerentes $(22 \%$ procedente, $6 \%$ procedente em parte, $6 \%$ de liminar deferida e $1 \%$ de liminar deferida parcialmente).

Por sua vez, somente $11 \%$ das ADIs (202 de 1.810 ADIs) sobre o processo decisório da União foram julgadas pró-requerente. ${ }^{8}$ Dessas, 128 ADIs anularam, total ou parcialmente, Emendas à Constituição, leis e medidas provisórias, porém, somente um terço durante a mesma legislatura e metade durante o mesmo governo que aprovou a legislação derrubada pela $\mathrm{ADI}$, quando considerado os períodos posteriores à reeleição presidencial. ${ }^{9}$

Essa conclusão corroborada por dados empíricos - o controle de constitucionalidade exercido pelo STF tem um papel concentrador nas relações entre entes federativos - está alinhada com algumas hipóteses presentes na literatura sobre o exercício da jurisdição constitucional (o abstract judicial review). Primeiro, confirma a proposição sobre a regra da absorção de Tsebelis (2009), a qual afirma que os tribunais não seriam atores com poder de veto de normas nacionais/federais, porque são absorvidos pelos outros veto players nacionais

\footnotetext{
7 Não há dados compilados sobre a quantidade de Emendas às Constituições Estaduais e de leis ordinárias/complementares sancionadas/promulgadas pelos estados brasileiros entre 1998 e 2013. Também não é simples estimar a quantidade, sobretudo, de leis estaduais relevantes sancionadas/sancionadas. Aqui consideradas como leis relevantes aquelas que tratam de políticas públicas, sociais e da administração pública estadual e não têm como objeto questões simbólicas como, por exemplo, declaração de utilidade pública, denominações, atribuição de honrarias ou declaração de datas festivas. Entretanto, a partir da base de dados mais ampla existente sobre proposições legislativas estaduais no período posterior a CF 1988 (organizada durante a última década pelo Grupo de Pesquisa "Instituições Políticas e Processo Legislativo", CNPq/UFPR; e, contendo mais de 160 mil proposições legislativas de 25 estados), só é possível observar 625 emendas e cerca de 30 mil leis estaduais relevantes promulgadas/sancionadas após a CF 1988. Ou seja, quase uma em cada dez leis relevantes e, possivelmente, mais da metade das emendas constitucionais estaduais foram objeto de ADI no STF. Este dado corrobora o impacto da jurisdição constitucional do STF via ADI no processo legislativo estadual. Sobre o processo legislativo estadual, ver Tomio e Ricci (2012a; 2012b) e Tomio (2012).

${ }^{8} \mathrm{Na}$ Tabela 1, no caso de uma ADI ter a liminar deferida e ser julgada procedente no mérito, esta Ação apenas é registrada no item procedente da tabela. Por sua vez, a ADI constará nas categorias liminar deferida, liminar deferida em parte e liminar indeferida apenas se não tiver sido apreciado o seu mérito.

${ }^{9}$ Mesmo não sendo uma quantidade irrelevante (40 a 60 ADIs derrubando legislação federal em 25 anos), a maioria dessas ações não poderiam ser classificadas como contramajoritárias, pelo menos em um sentido de derrubar propostas legislativas do governo/coalizão parlamentar que as aprovou por inciativa de minorias parlamentares. Parte significativa dessas ADIs que obtiveram sucesso coalizões majoritárias foram propostas por: associações/confederações (22 ADIs), tratando de interesse corporações jurídicas e normas tributárias de interesses de entidades empresariais; Partidos Políticos (22 ADIs), que seriam tipicamente contramajoritários, tratam de vários temas nas ADIs ("registro de armas", "notários", "direitos trabalhistas" e de "servidores públicos"), mas, o principal objeto é "legislação política e eleitoral"; o Procurador Geral da República (PGR, 13 ADIs), o requerente mais complexo na derrubada de leis federais através de ADI, inclui em seu rol de ações bem sucedidas de direitos de minorias/vulneráveis aos interesses corporativos do Ministério Público.
} 
(governo, parlamentos, partidos, instituições nacionais). Desse modo, os tribunais não agiriam, como regra, de maneira contra majoritariamente ao decidir em controle abstrato sobre legislação aprovada pela coalizão majoritária da união em conflitos entre normas nacionais e subnacionais.

Ainda, a pesquisa de Tomio e Robl (2013) corrobora a validade da proposição de Bzedera (1993) que, basicamente, sustenta que o controle abstrato de constitucionalidade tem como objetivo restringir a federação/descentralização a partir de dispositivos/prerrogativas consolidadas constitucionalmente pelo poder central. $\mathrm{O}$ arranjo institucional e a distribuição de competências entre os níveis de governo passam a serem fatores explicativos centrais sobre as decisões que envolvem o controle federativo/descentralização. Ou seja, as determinações constitucionais do arranjo federativo/relações intergovernamentais e de suas instituições judiciais (notadamente, seleção e composição) aumentam a probabilidade dos tribunais constitucionais promoverem a centralização política, na medida em que não impedem as iniciativas legislativas centralizadoras do governo federal e limitam as iniciativas dos governos locais/unidades federadas.

Após a comprovação de que as ADIs atuam de forma determinante na estrutura federativa brasileira, já que restringem o poder normativo dos estados-membros, a pesquisa sobre a jurisdição constitucional e o federalismo, nesse momento, volta-se para os impactos da atuação dos Tribunais de Justiça (TJs) no desenho federal. Antes, entretanto, cabe situar comparativamente o federalismo brasileiro historicamente.

\section{FEDERALISMO BRASILEIRO EM PERSPECTIVA HISTÓRICA E COMPARADA NA CONSTITUIÇÃO FEDERAL DE 1988}

Todos os entes federativos brasileiros preveem em suas constituições estaduais Representações de Inconstitucionalidade ou Ações de Direta de Inconstitucionalidade, permitindo que os TJ declarem atos normativos estaduais ou municipais contrários à Constituição estadual ${ }^{10}$. Assim, o maior ou menor exercício da declaração de

\footnotetext{
${ }^{10}$ A única forma de impugnar de forma concentrada um ato normativo municipal em relação à Constituição Federal dá-se pelo manejo de Arguição de Descumprimento de Preceito Fundamental (ADPF), regulamentada pela Lei Federal nº 9868/98. O parâmetro de análise desta Ação é mais estreito do que da ADI no STF, pois a ADPF apenas é cabível na violação de preceito importante (fundamental) da Constituição.
} 
inconstitucionalidade estadual de atos normativos estaduais e municipais pode restringir as autonomias municipais e estaduais.

A grande hipótese a ser testada neste artigo reside no impacto das ADIs estaduais na ampliação da centralização da Federação brasileira e, principalmente, nos efeitos que produz na autonomia municipal. Ou seja, se os Tribunais de Justiça replicam aos municípios o perfil decisório do STF em relação à legislação municipal. Por óbvio, para compreendermos adequadamente o resultado da jurisdição constitucional estadual sobre o pacto federativo, impõe-se entender a distribuição de competências administrativa e legislativa entre os entes federativos no Brasil.

Desse modo, far-se-á uma análise da federação brasileira no tempo, assim como a comparação da estrutura brasileira com outros modelos federativos contemporâneos ${ }^{11}$. A forma federativa adotada na República Velha segue o modelo norte-americano com razoável autonomia às entidades subnacionais ${ }^{12}$. Esse desenho institucional promoveu um federalismo dual, em que existia uma distribuição de competências mais rígidas entre os entes federativos (união e estados-membros). Assim, os estados-membros economicamente mais fortes (São Paulo e Minas Gerais) foram beneficiados com o modelo, tendo menor espaço a construção de políticas nacionais e projetos de redução das desigualdades regionais promovida pela união.

$\mathrm{Na}$ Constituição brasileira de 1934, desenhou-se um modelo federal centralizado, restringindo o processo de produção legislativa nas unidades subnacionais ${ }^{13}$.Atualmente, o texto constitucional, além de detalhista na descrição das competências da União, dos Estados e dos Municípios, mantém o perfil centralista.

Por meio da: a) distribuição nas Constituições brasileiras republicanas das competências legislativas e administrativas (da União e dos Estados) e as prerrogativas de iniciativa legislativa (do executivo e legislativo estadual) e b) da construção dos indicadores das competências constitucionais com a atribuição do valor entre " 0 " (máxima da descentralização legislativa e administrativa atribuída aos Estados - privativas/exclusivas dos Estados) e "1" (máximo da centralização legislativa e administrativa concedida à União -

\footnotetext{
${ }^{11}$ Cf. Tomio e Ricci (2012a) e Tomio, Ortolan e Camargo (2010).

${ }^{12}$ Apesar de o Brasil ser um Estado unitário no período imperial, discussões e disputas sobre o poder das províncias são bastante vivas nesse momento. De outro lado, formalmente, o tipo federativo é incorporado na realidade brasileira com a República e a Constituição de 1891. Sobre a história do federalismo no Brasil, cf. Marrafon (2014).

${ }^{13}$ Não se sustenta neste artigo a ausência de diferenças importantes nas Constituições brasileiras após 1934, as quais obviamente existem e são fundamentais como a adoção de regimes políticos democrático ou autoritário. Por sua vez, as Constituições brasileiras desde 1934 e inclusive a de 1988 promovem em linhas gerais a centralização federativa.
} 
privativas/exclusivas da União), é possível mensurar a centralização federativa na história brasileira $^{14}$.

O Gráfico 1 abaixo, utilizando esses indicadores, demonstra que a maior centralização das competências legislativas e administrativas em regime democrático foi promovida pelo desenho institucional da Constituição Federal de 1988. Também em relação às distribuições das prerrogativas de iniciativa legislativa, a Constituição Federal vigente promove a preponderância do Executivo sobre o Legislativo. ${ }^{15}$

\section{Gráfico 1 - Distribuição Constitucional de Competências}

Legislativas/Administrativas

(Estados X União)

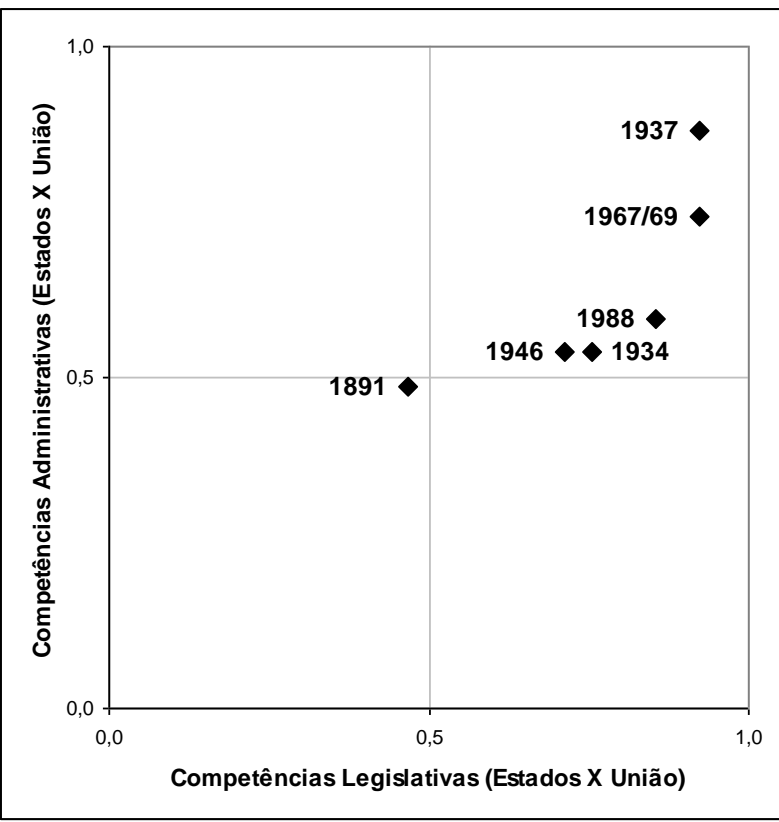

Legislativas (Estados X União) e Prerrogativas de Iniciativa Legislativa (Legislativo X Executivo)

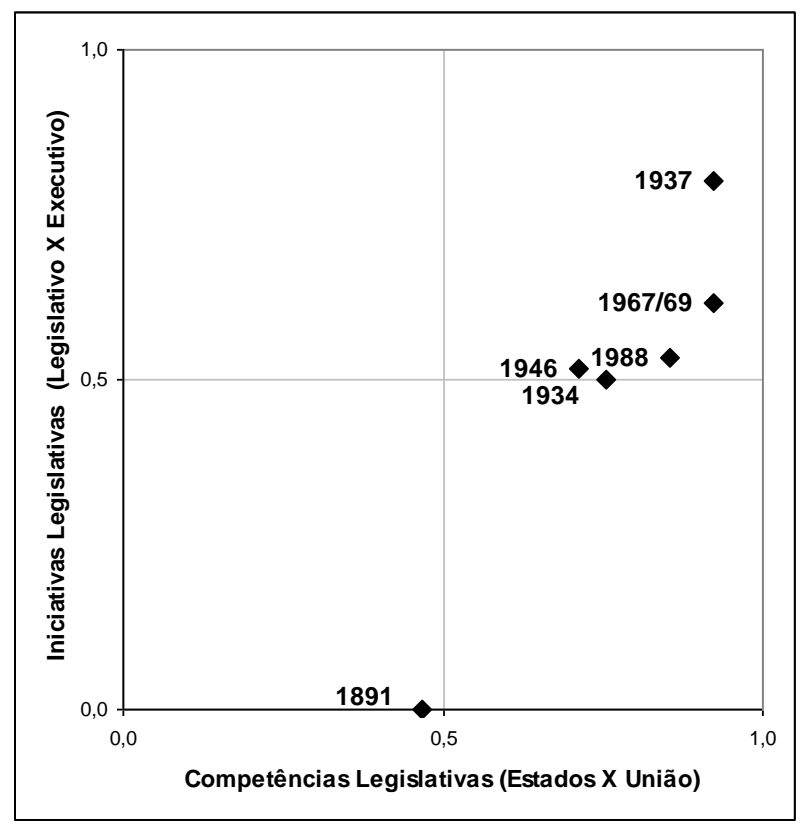

\footnotetext{
${ }^{14}$ Cf. Tomio e Ricci (2012a).

15 Evidencia-se ainda forte centralização do modelo brasileiro na comparação entre as competências e as prerrogativas da união com relação aos entes subnacionais com outras federações. Tomio, Ortolan e Camargo (2010, p. 77-82), comparando o Brasil a sete federações (Alemanha, Argentina, Austrália, Áustria, Estados Unidos, Índia e Suíça), demonstraram que o Brasil, na CF 1988, é o pais em que as competências legislativas encontram-se mais centralizadas, assim como é a terceira federação mais centralizada administrativamente. Os autores chegam a esta conclusão por meio de pesquisa documental comparada com: a) interpretação dos textos constitucionais federais das referidas federações a partir dos parâmetros fixados nos artigos 21 a 24 da Constituição brasileira e da literatura especializada, b) construção de indicadores para comparação das competências legislativas e administrativas que consideram o conteúdo (matéria) e a extensão (participação de um ou mais entes federativos), c) adoção de critério descentralização/centralização mensurável para avaliar a distribuição de competências concedida às unidades subnacionais e à União nas constituições federativas (TOMIO, ORTOLAN e CAMARGO, 2010).
} 
Fonte: Tomio e Ricci (2012a, p. 80-1).

\section{CONSTITUCIONALISMO ESTADUAL BRASILEIRO E AUTONOMIA MUNICIPAL}

Além de forte restrição aos legislativos estaduais no processo de decisão legislativa infraconstitucional, a limitação ao legislativo estadual também é substancial na elaboração de constituições estaduais. A constituição federal de 1988, no art. 25, caput, impõe a observância dos princípios estruturais do constitucionalismo federal nas cartas estaduais ${ }^{16}$.

Há relevante discussão, na teoria do federalismo, de como equilibrar as autonomias administrativa e legislativa dos entes subnacionais (no caso brasileiro, principalmente estados membros e municípios) com certa observância da estrutura estatal desenhada pela constituição federal para a união. No bojo desse debate, aparece a discussão sobre o princípio da simetria, a qual é vista como, de um lado, a observância das estruturas centrais da constituição federal nas constituições estaduais e, de outro lado, certa padronização na conformação estatal e constitucional dos estados membros ${ }^{17}$.

Por sua vez, a jurisprudência do Supremo Tribunal Federal estabeleceu interpretação do princípio da simetria que foca na necessidade de reprodução de boa parte da disciplina do constitucionalismo federal nas constituições estaduais ${ }^{18}$. O efeito dessa interpretação do STF

\footnotetext{
${ }^{16}$ Assim prescreve o texto constitucional: “Art. 25. Os Estados organizam-se e regem-se pelas Constituições e leis que adotarem, observados os princípios desta Constituição”.

${ }^{17}$ Cf. Tarlton (1965). Sobre o princípio da simetria, assim se manifesta Watts (2000): "If we take Tarlton's 1965 article about asymmetry within federal systems as a starting point for defining symmetry and asymmetry, we must first note that the terms symmetry and asymmetry are applied to relationships within a federal system. The relationships to which he applies the terms are the ways in which a member state within a federal political system relates to the system as a whole, to the federal authority, and to each other member state. In these relationships he defined symmetry as 'the level of conformity and commonality in the relations of each separate political unit of the system to both the system as a whole and to the other component units'. In other words, it relates to the uniformity among member states in the pattern of these relationships within a federal system. He went on to suggest that in an ideal symmetrical federal system each state would maintain essentially the same relationship to the federal authority, the division of powers between the federal and state governments would be virtually the same in every case, representation in the federal government would be on the same basis for each component polity, and support of the activities of the federal government would be equally distributed. Asymmetry in a federal system, on the other hand, refers to a situation where the diversities within the larger society find political expression through component governments 'possessed of varying degrees of autonomy and power'. A component unit would have about it 'a unique feature or set of features" which distinguishes its relationship to the system as a whole, to the federal authority, and to each other state"".

${ }^{18}$ Sobre o princípio da simetria no STF, cf. ADI 486 impõe a observância do quorum para aprovar emenda à constituição federal no constitucionalismo estadual e ADI 3647 determina a observância do regime de impedimento e afastamento do Presidente da República para os governadores de Estado.
} 
sobre a simetria é dificultar que o constitucionalismo estadual possa desenvolver fórmulas inovadoras sobre a organização do Estado e a garantia dos direitos e funcionar como um laboratório de experiências constitucionais ${ }^{19}$.

Assim como existe o controle concentrado e abstrato de constitucionalidade no STF previsto na constituição federal, o constituinte estadual pode estabelecer ações direitas de inconstitucionalidade ou representações de inconstitucionalidade para proteção da constituição estadual, sendo competente para análise dos tribunais de justiça e vedando-se a atribuição de um único legitimado ativo, nos termos do art. 125, §2, constituição federal de $1988^{20}$

Sobre o poder de as Assembleias Legislativas disciplinarem as ADI estaduais, restou decidido pelo STF que: a) não é possível por meio dessas ações os TJs declararem leis municipais inconstitucionais por violação à constituição federal ${ }^{21}$ e b) não é válida a prescrição de que o legislativo estadual precisa suspender a eficácia de atos normativos estaduais ou municipais julgados inconstitucionais pelas ADIs estaduais ${ }^{22}$.

Importante observar que originalmente as ADIs estaduais eram relevantes mecanismos de controle concentrado dos atos normativos municipais, pois até o advento da arguição de descumprimento de preceito fundamental (ADPF) o STF não realizava controle concentrado das leis municipais por meio da constituição federal. Nesse contexto, para buscar a invalidade de normas municipais de forma concentrada, somente existia a via das Ações Direitas de Inconstitucionalidade Estaduais a partir do texto da Constituição Estadual.

Desse modo, através de ADIs estaduais, há relevante instrumento para controle e restrição das autonomias municipais, sobretudo, e estaduais no Estado federal brasileiro que já é muito centralista. Como será visto nos dados apresentados neste artigo, essas ações atacam principalmente e com mais intensidade a autonomia municipal.

\footnotetext{
${ }^{19}$ A função inovadora do constitucionalismo estadual é apresentada por Levinson (2014, p. 591) no modelo norte-americano: "Still, I want to suggest that we need, at least as much, to be far more sensitive to the way that the states have served as similar laboratories with regard to ways of structuring their basic institutions. Sometimes a state's choice is quite dramatic, as with Nebraska's unicameralism; other choices are likely to be known only to the cognoscenti, such as the power given the Tennessee Supreme Court to select the state's attorney general. Equally esoteric, but of genuine interest, is the requirement that the members of the Tennessee Supreme Court come from the three regions of the Volunteer State,48 in vivid contrast to the current membership of the United States Supreme Court, which has not received a new justice then living west of the Mississippi since Anthony Kennedy's appointment in 1987'

${ }^{20}$ Para uma análise da regulamentação de todas as Ações Diretas de Inconstitucionalidade nas Constituições Estaduais brasileiras e um estudo da sua conformidade com o princípio da simetria conforme interpretação do STF, cf. Sgarbossa (2014).

${ }^{21}$ Ação Direta de Inconstitucionalidade nº. 409/RS

${ }^{22}$ Recurso Extraordinário nº ${ }^{\circ}$ 199.293-0/SP.
} 
Essa autonomia não é recente e foi obtida na Constituição de 1946 (no aspecto administrativo e financeiro) (MEIRELLES, 2006, p. 42). Entretanto, o município brasileiro detém particularidades que o diferem de outras configurações administrativas de outros países. Como afirma Pontes de Miranda, ao se referir sobre o Brasil, “o Município é entidade intra-estatal rígida, como a União e o Estado-membro (...). Fujamos à busca no Direito NorteAmericano e Argentino, porque a concepção brasileira de autonomia municipal é diferente" (PONTES DE MIRANDA, p. 345).

Na Constituição de 1988, o Município foi erigido à condição de ente federativo (art. $1^{\circ}$ e 18). A consequência foi o aumento do grau de autonomia municipal, especialmente com relação às competências políticas (eleição de prefeitos e vereadores), embora tenha surgido a vedação à criação de Tribunais, Conselhos ou órgãos de Contas municipais (art. 31, §4).

No tocante às competências legislativas, a Constituição de 1988 lhe concedeu a competência de elaborar sua Lei Orgânica (art. 29), legislar sobre assuntos de interesse local (art. 30, I), sobre seus orçamentos e tributos, além de poder suplementar a legislação federal e estadual no que couber (art. 30, III).

Em comparação entre as prerrogativas dos governos locais e a institucionalização da autonomia municipal no sistema jurídico das Federações Alemanha, Argentina, Austrália, Austria, Brasil, India, Estados Unidos e Suíça, o Brasil possui a maior concessão de autonomia ao governo local (TOMIO, CAMARGO, ORTOLAN, 2011). Apesar da grande autonomia, a competência legislativa do município na Federação brasileira é restrita, já que a concentração das competências legislativas ocorreu na União.

\section{CONTROLE JUDICIAL DE CONSTITUCIONALIDADE ESTADUAL: HIPÓTESES E DADOS DAS ADI ESTADUAIS ${ }^{23}$}

Atualmente, observa-se um desenvolvimento mais consistente sobre o controle judicial da constituição do estado-membro ou das entidades subnacionais ${ }^{24}$.Por exemplo,

\footnotetext{
${ }^{23}$ Os dados sobre as ADI estaduais apresentados neste artigo foram levantados com participação dos acadêmicos de Metodologia da Pesquisa Científica em Direito da Faculdade de Direito da UFPR e de pesquisadores do Núcleo de Direito e Política (DIRPOL) do Programa de Pós-Graduação em Direito da UFPR. Um especial agradecimento deve ser feito ao pesquisador Marcus Paulo Röder pela participação no levantamento de dados. Uma versão preliminar dos resultados e dos argumentos desta seção, com uma análise/classificação parcial dos dados coletados, foi apresentada no IX Encontro da ABCP (Brasília-DF, 04 a 07/08/2014).

${ }^{24}$ Por exemplo, na Alemanha, no México e nos Estados Unidos, ver, respectivamente, Freitag, Vatter, (2009); Emmert (1992); Garza (2014).
} 
Emmert (1992) apresenta as seguintes hipóteses sobre a intensidade do controle judicial das Constituições estaduais por uma Suprema Corte Estadual ou Tribunal de Justiça Estadual: a) quanto mais extensa for a Constituição Estadual, há um aumento no exercício do controle judicial estadual e b) quando o ato da Suprema Corte Estadual ou Tribunal de Justiça Estadual não pode ser revisto pela Suprema Corte Nacional ou Corte Constitucional, a intensidade do controle de constitucionalidade estadual da carta estadual aumenta.

No Brasil, as Constituições estaduais, assim como a Constituição Federal, são analíticas (extensas). Sobre o poder de revisão do STF sobre julgamento de ADI estadual, se a norma da Constituição Estadual violada tratar-se de norma existente na Constituição Federal, é possível interpor recurso extraordinário. Em caso de a norma da Constituição Estadual não encontrar correspondência na carta federal, não cabe recurso da decisão tomada pelo TJ.

Tomio e Robl (2013) já demonstraram que as ADIs propostas no STF atuam com maior intensidade sobre atos normativos estaduais do que nas normas federais, gerando como impacto uma maior centralização. Desse modo, há necessidade de verificar se as ADIs estaduais declaram com mais frequência normas municipais inconstitucionais do que atos normativos estaduais. Por sua vez, existe uma tendência no federalismo brasileiro de atribuir maior poder nas mãos do Executivo, precisando ser compreendido em que medida as Ações estaduais atuam na promoção ou não de competências do Executivo.

Desse modo, as hipóteses a serem verificadas podem ser assim apresentadas:

H1 - Os TJs são relevantes atores políticos no processo de tomada de decisão política e jurídica, declarando inconstitucionais atos normativos estaduais e municipais e ampliando a centralização federativa brasileira em razão da extensão do texto das Constituições Estaduais e das restrições à revisão dessas decisões pelo STF;

H2 - O controle de constitucionalidade é mais forte em relação aos atos normativos municipais do que sobre os atos estaduais, pois o órgão julgador do Tribunal de Justiça possui menor relação institucional com os órgãos e as autoridades que produzem normas municipais e o papel de controle federativo dos atos normativos estaduais, sobretudo legislação, foi delegado ao STF;

H3 - Os fundamentos para declaração de inconstitucionalidade dos atos normativos encontram-se em vícios formais (iniciativa e competência) e não em questões materiais; 
H4 - O controle de constitucionalidade estadual protege as competências e prerrogativas do Executivo municipal, restringindo o poder do Legislativo.

Como base empírica da verificação destas hipóteses, o artigo analisa 19.196 ações diretas de inconstitucionalidade estaduais, julgadas no período de 1990 a $2013 .{ }^{25} \mathrm{Na}$ Tabela 2 é possível observar claramente a validade empírica da segunda hipótese (e, parcial, da primeira hipótese, dado a quantidade de ADIs). A distribuição das ADIs por Unidade da Federação e a classificação da esfera federativa dos atos normativos atacados evidencia, preliminar e robustamente, que o foco das ADIs nos TJs é majoritariamente direcionado às normas e atos municipais.

Tabela 2 - ADI Estaduais por Região, Estado-Membro, Atos Normativos Atacados

\begin{tabular}{c|c|c|c|c}
\hline UF & Estadual & Municipal & $\begin{array}{c}\text { Sem } \\
\text { Classificação }\end{array}$ & Total \\
\hline Centro-Oeste & $\mathbf{1 4 3}$ & $\mathbf{6 5 4}$ & $\mathbf{3 0}$ & $\mathbf{8 2 7}$ \\
\hline GO & 89 & 438 & & 527 \\
MS & 36 & 89 & 15 & 140 \\
MT & 18 & 127 & 15 & 160 \\
\hline Nordeste & $\mathbf{8 2}$ & $\mathbf{5 4 8}$ & $\mathbf{5 9}$ & $\mathbf{6 8 9}$ \\
AL & 4 & 64 & & 68 \\
BA & 3 & 11 & & 14 \\
CE & 3 & 27 & 4 & 34 \\
MA & 13 & 34 & & 47 \\
PB & 25 & 273 & 42 & 340 \\
PE & 2 & 26 & 1 & 29 \\
PI & 3 & 30 & 8 & 41 \\
RN & 11 & 44 & 2 & 57 \\
SE & 18 & 39 & 2 & 59 \\
\hline Norte & $\mathbf{3 3}$ & $\mathbf{1 2 7}$ & $\mathbf{4}$ & $\mathbf{1 6 4}$ \\
\hline AC & 3 & 4 & & 7 \\
AM & & 2 & & 2 \\
AP & 2 & 7 & & 9 \\
PA & 6 & 65 & 4 & 75 \\
RO & 12 & 19 & & 31 \\
RR & 2 & 1 & & 3 \\
TO & 8 & 29 & $\mathbf{1 0 . 2 9 1}$ & 326 \\
\hline Sudeste & $\mathbf{6 0 5}$ & 293 & 20 & \\
\hline ES & 13 & & & \\
\hline
\end{tabular}

${ }^{25}$ O levantamento da jurisprudência permitiu catalogar 780 ADIs julgadas pelo Tribunal de Justiça do Distrito Federal entre 1990 e 2013. Entretanto, como o foco desse artigo está na autonomia municipal, os dados do TJDF não foram incorporados à análise aqui exposta. 


\begin{tabular}{c|ccc|c} 
MG & 42 & 2.286 & 1.019 & 3.347 \\
RJ & 461 & 1.863 & 62 & 2.386 \\
SP & 89 & 5.797 & 190 & 6.076 \\
\hline Sul & $\mathbf{3 4 5}$ & $\mathbf{4 . 8 4 0}$ & $\mathbf{1 9 6}$ & $\mathbf{5 . 3 8 1}$ \\
\hline PR & 76 & 902 & 50 & 1.028 \\
RS & 97 & 2.622 & 31 & 2.750 \\
SC & 172 & 1.316 & 115 & 1.603 \\
\hline Total & $\mathbf{1 . 2 0 8}$ & $\mathbf{1 6 . 4 0 8}$ & $\mathbf{1 . 5 8 0}$ & $\mathbf{1 9 . 1 9 6}$ \\
\hline$(\%)$ & $\mathbf{6 , 9 \%}$ & $\mathbf{9 3 , 1 \%}$ & & \\
\hline
\end{tabular}

Fonte: Jurisprudência (TJ), base de dados organizada pelos autores.

Sendo mais preciso nesta constatação, 93,1\% das ADIs julgadas nos Tribunais estaduais atacam atos normativos municipais e 6,9\% atos normativos estaduais. Essa constatação não poderia sequer ser contrastada com a impossibilidade de classificação do ente autor do ato normativo em cerca de $8 \%$ dos casos. Infelizmente, como a jurisprudência dos tribunais disponível nos sítios eletrônicos dos TJ não se apresenta completa e uniforme, não foi possível realizar a classificação do nível federativo da norma atacada em 1.580 ADIs estaduais, porém a tendência é que essas ações não alteram significativamente a proporção de distribuição. ${ }^{26}$ Ou seja, mesmo que todas ADIs "não classificadas" (cf. Tabela 2) atacassem atos normativos estaduais, ainda assim mais de $85 \%$ das ADIs seriam direcionadas a normas municipais. O mais provável, segundo os dados disponíveis, é que cerca de dezenove em cada vinte ADIs julgadas nos tribunais analisados questionem atos e normas municipais, tornando clara a validade da segunda hipótese.

\section{Gráfico 2 - Quantidade de ADI (UF) por Receita Fiscal (UF) (TJ; 1990-2013)}

\footnotetext{
${ }^{26}$ As fontes básicas de coleta de dados da jurisprudência foram os sítios eletrônicos dos TJs. Parte dos dados obtidos não foi possível de classificação pelos indicadores construídos para análise desse texto, em geral por que essas informações (norma atacada, ementa, requerente, etc.). Entretanto, os dados passíveis de classificação permitem a análise e descrição do processo de jurisdição constitucional por ADI que foram julgados nos 26 TJ estaduais entre 1990 e 2013. Nas tabelas seguintes, a quantidade de ADI não classificadas serão expressas como data missing e informadas junto com a referência à fonte de informações.
} 


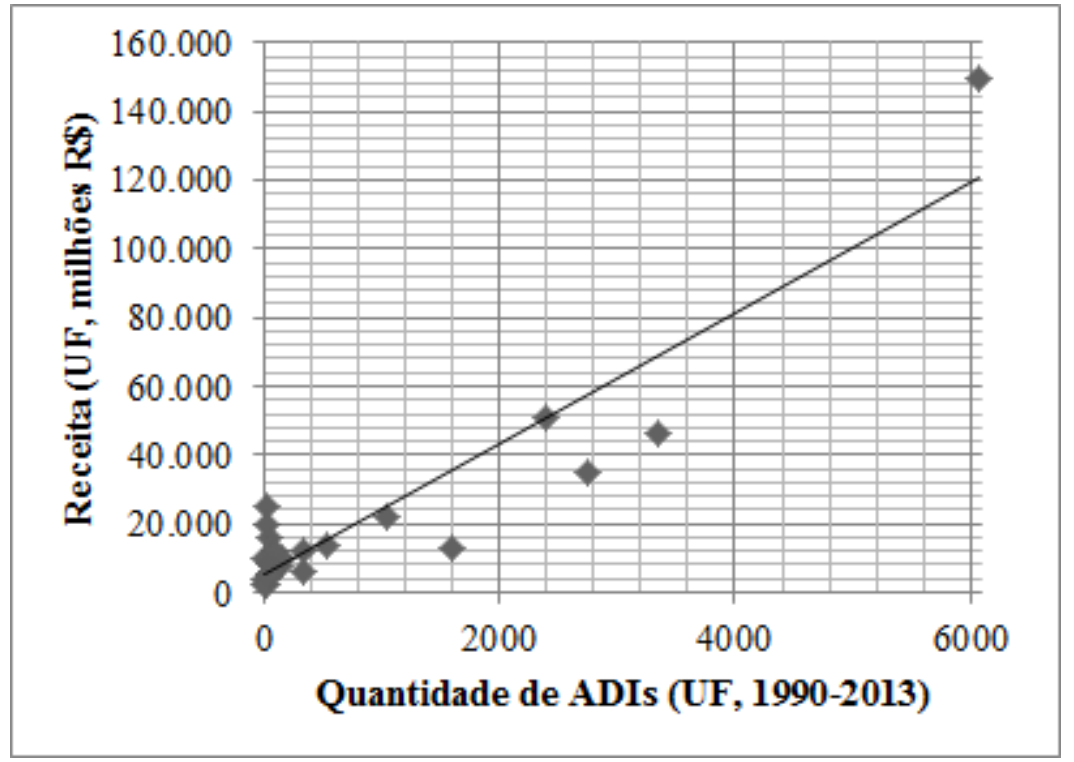

Fonte: STN (Secretaria Tesouro Nacional); Jurisprudência (TJ), base de dados organizada pelos autores.

Além disso, percebe-se que a quantidade de ADIs estaduais julgada em cada TJ está fortemente correlacionada com a receita fiscal do estado-membro (UF). Isso indica que quanto mais complexa a administração pública, maior a receita do estado ${ }^{27}$ e, por decorrência, dos municípios que compõem a UF, maior a demanda dos requerentes legitimados pela judicialização de ADI como um meio de nulificar alguma norma municipal e estadual (ver Gráfico 2). Aqui, com este dado, pretendemos demonstrar que a judicialização está concentrada em poucos estados devido, principalmente, à complexidade da administração pública municipal dessas unidades federativas e, por decorrência, da possibilidade de competição legislativa (entre legislativo e executivo municipal e município e Estado) pela forma de normatizar a alocação de recursos disponíveis em políticas e gestão públicas. Não se trata, simplesmente, de um ímpeto legislativo local ou de uma inépcia de compreender os princípios constitucionais replicados nas cartas estaduais, mas, possivelmente, o desejo de

\footnotetext{
${ }^{27}$ Utiliza-se aqui a receita orçamentária estadual como um proxy das receitas disponíveis aos municípios pela incapacidade de classificar e individualizar as ADI por municípios de cada estado. Possivelmente, caso isto fosse feito, perceberíamos que as ADIs não focam municípios pequenos e com parcas receitas municipais. De fato, segundo o Boletim de Notícias do Conjur, com base nos dados do Anuário da Justiça de São Paulo 2015: "De cada quatro municípios do estado de São Paulo, um teve pelo menos uma lei considerada inconstitucional pelo Órgão Especial do Tribunal de Justiça de São Paulo em 2014, considerados os julgamentos ocorridos de janeiro a novembro. A campeã absoluta de inconstitucionalidades foi São José do Rio Preto, rica cidade de 440 mil habitantes situada no noroeste paulista, a 450 quilômetros da Capital. Das 48 normas rio-pretenses levadas à análise da Justiça, nada menos do que 42 foram consideradas em desacordo com a Constituição do estado, ou com a Constituição Federal, ou com ambas. Todas elas são frutos do desentendimento permanente entre o prefeito, autor de quase todas as ações, e os vereadores - quase sempre reprovados por estarem fazendo algo que não é da alçada deles” (CONJUR, 2015).
} 
aumentar a esfera autônoma legislativa local sobre problemas que poderiam ser alocados os escassos, porém disponíveis, recursos municipais.

\section{Gráfico 3 - ADI por ANO de julgamento (TJ; 1990-2013)}

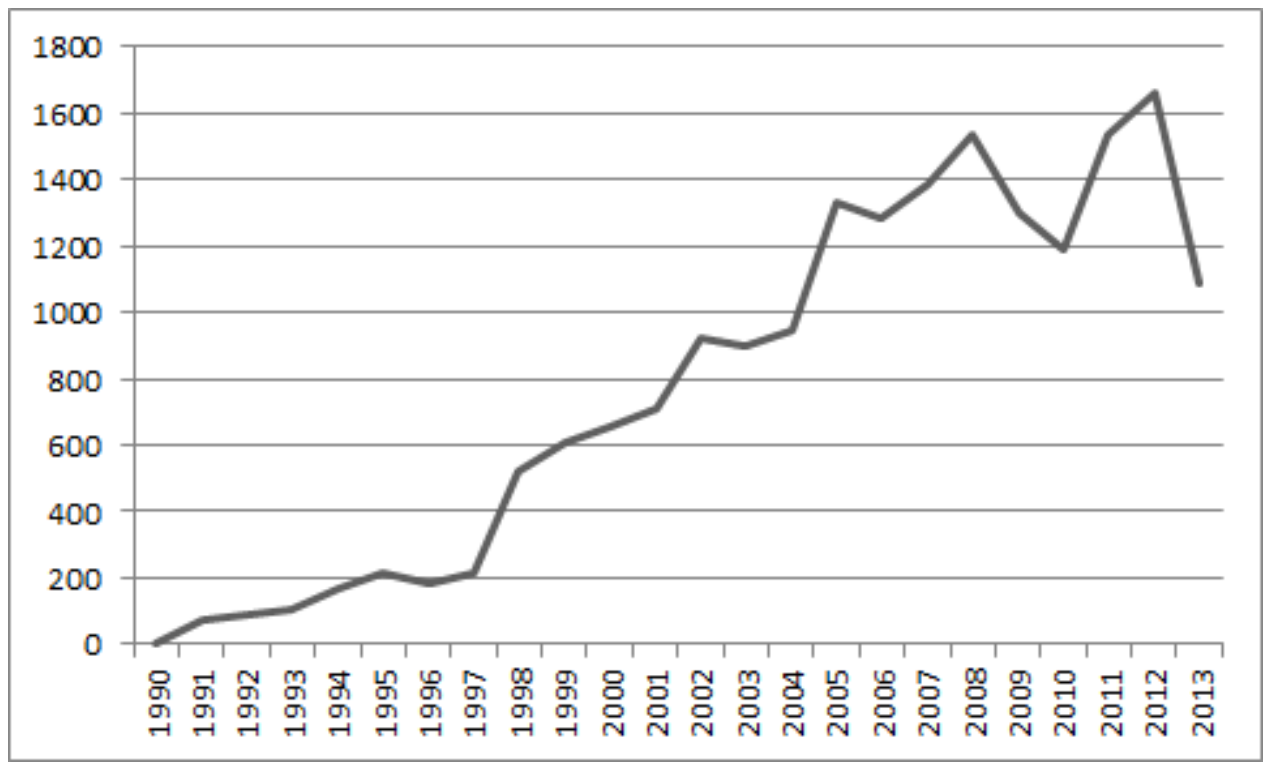

Fonte: Jurisprudência (TJ), base de dados organizada pelos autores [data missing $=453$ ].

Além disso, há uma ampliação substancial da utilização das ações diretas de inconstitucionalidade conforme avança o processo legislativo posterior a CF 1988 e a promulgação das Constituições Estaduais. Isto pode ser visualizado no Gráfico 3, período de 1990 a 2013. Isto indica quem, apesar das oscilações recentes, a frequência de litígios em normas municipais resolvidos pela judicialização de ADIs nos TJs continuará sendo uma forma de garantir a distribuição de competências e a centralização federativa brasileira.

Voltando as duas primeiras hipóteses apresentadas, a Tabelas 4 permite verificar de forma mais clara a validade explanatória e empírica de ambas. Além de as ações diretas de inconstitucionalidade estaduais serem um dispositivo bastante utilizado para judicializar atos normativos estaduais e, sobretudo, municipais, a taxa de sucesso pró-requerente é bastante elevada. Porém, quando a norma atacada é municipal, o percentual de nulificação via ADI supera os três quartos das ações. Por um lado, a nulificação de dezenas de atos normativos estaduais e municipais demonstra que os TJs são relevantes atores políticos no processo decisório das unidades federativas e favorecem a ampliação da centralização federativa brasileira. Por outro, claramente o controle de constitucionalidade via ADI é mais presente, 
em número e taxa de sucesso pró-requerente, em relação aos atos normativos municipais do que sobre os atos estaduais, indicando que os TJs ocupam-se preferencialmente da limitação da descentralização na esfera municipal enquanto o STF atua no controle federativo dos atos normativos estaduais.

Tabela 4 - ADI por RESULTADO e Origem da Norma (TJs; 1990-2013)

\begin{tabular}{l|c|c|c|c}
\hline \multirow{2}{*}{ Resultado Julgamento } & \multicolumn{2}{|c|}{ Estadual } & \multicolumn{2}{c}{ Municipal } \\
\cline { 2 - 5 } & $\mathbf{n}$ & $\mathbf{\%}$ & $\mathbf{n}$ & $\mathbf{\%}$ \\
\hline ADI Contra Requerente (total) & $\mathbf{6 1 0}$ & $\mathbf{5 3 , 8 \%}$ & $\mathbf{3 . 9 6 9}$ & $\mathbf{2 4 , 7 \%}$ \\
Extinto & 200 & & 1.670 & \\
Improcedente & 238 & & 1.760 & \\
Indeferida & 46 & & 266 & \\
Não conhecida & 53 & & 116 & \\
Prejudicado & 73 & & 157 & \\
\hline ADI Pró-Requerente (total) & $\mathbf{5 2 3}$ & $\mathbf{4 6 , 2 \%}$ & $\mathbf{1 2 . 0 7 2}$ & $\mathbf{7 5 , 3 \%}$ \\
Deferida Liminar total ou parcialmente & 74 & & 767 & \\
Procedente totalmente & 410 & & 10.430 & \\
Procedente em parte & 39 & & 875 & \\
\hline Total & $\mathbf{1 . 2 0 8}$ & \multicolumn{1}{|c|}{$\mathbf{1 6 . 4 0 8}$} & \\
\hline
\end{tabular}

Fonte: Jurisprudência (TJ), base de dados organizada pelos autores [data missing $=2.022$ ].

A classificação detalhada das ADIs para mensurar o êxito, expressa na Tabela 4, permite compreender melhor esse processo. Essa classificação é composta pelas categorias pró-requerente e contra requerente, encontrando-se naquela classificação as ações a) com liminar deferida total ou parcialmente e sem decisão de mérito, b) com decisão de mérito de procedência total ou c) com decisão de mérito com procedência parcial do pedido. Por sua vez, compõe o item contra requerente as ações a) extintas, b) não conhecidas, c) com liminar indeferida, d) improcedentes no mérito, e) pendente o julgamento de mérito e f) prejudicadas.

Como visto, nas ADIs que atacam os atos estaduais, uma em cada duas ações é decidida pró-requerente aproximadamente. Ainda, o sucesso de declaração de normas municipais inconstitucionais é maior, sendo pró-requerente cerca de três em quatro ADI. Além disso, a decisão final e não liminar pró-requerente contra normas municipais é mais acentuada. Aproximadamente $95 \%$ das decisões pró-requerentes são procedentes, no mérito, nas normas municipais, enquanto cerca de $85 \%$ tem esse tipo de decisão nas normas estaduais tem essa decisão pró-requerente. A diferença percentual é pequena. Entretanto, como a quantidade absoluta é muito ampla, o efeito é que muito mais normas municipais são tornadas 
nulas via ADI em caráter final e não liminar. Se a distribuição fosse semelhante, cerca de mil normas municipais poderiam ter sua decisão revertida no julgamento de mérito.

Ainda é relevante compreender os fundamentos constitucionais que sustentam os pedidos de inconstitucionalidade, que podem ser categorizados como formais ou materiais. Aquela classificação possui como espécies a) os vícios de competência, b) a violação da competência de iniciativa do processo ou c) outra questão formal, sendo a alegação material, por exclusão, uma situação não processual como a violação de um direito ou conteúdo previsto na Constituição estadual.

Conforme o postulado na terceira hipótese apresentada, os dados demonstram que os fundamentos para declaração de inconstitucionalidade dos atos normativos encontram-se em vícios formais (iniciativa e competência) e não em questões materiais (ver Tabelas 5 e 6). A grande maioria dos requerentes nas ADIs possui fundamentos constitucionais formais, sendo quase três de cada quatro estruturadas com essas justificativas. Deve-se registrar que o parâmetro formal de violação constitucional é substancialmente maior nas ações contra atos normativos municipais $(72,3 \%)$ do que as contra normas estaduais $(55,2 \%)$.

Interessante e importante registrar, como reforço da validade da terceira hipótese e já indicando a acuidade da quarta hipótese apresentada, que apesar de os argumentos formais serem quantitativamente hegemônicos, a taxa de sucesso nas ações que apresentam fundamentos sobre vício de iniciativa é superior a qualquer outro argumento formal ou material, obtendo êxito em $87,9 \%$ (ver Tabela 6$).^{28}$

Tabela 5 - ADI por Vício de Inconstitucionalidade e Origem da Norma (TJs; 1990-2013)

\begin{tabular}{l|c|c|c|c}
\hline \multirow{2}{*}{$\begin{array}{l}\text { Vício de } \\
\text { Inconstitucionalidade }\end{array}$} & \multicolumn{2}{|c|}{ Estadual } & \multicolumn{2}{c}{ Municipal } \\
\cline { 2 - 5 } & $\mathbf{n}$ & $\mathbf{\%}$ & $\mathbf{n}$ & $\mathbf{\%}$ \\
\hline COMPETÊNCIA & 81 & $12,6 \%$ & 1.092 & $8,7 \%$ \\
\hline INICIATIVA & 233 & $36,2 \%$ & 7.477 & $59,2 \%$ \\
\hline OUTRA QUESTÃO FORMAL & 41 & $6,4 \%$ & 552 & $4,4 \%$ \\
\hline MATERIAL & 288 & $44,8 \%$ & 3.500 & $27,7 \%$ \\
\hline
\end{tabular}

Fonte: Jurisprudência (TJ), base de dados organizada pelos autores [data missing $=5.932$ ].

\footnotetext{
28 Provavelmente, dado que o data missing é relativamente elevado na classificação do "vício de inconstitucionalidade" (quase seis mil ADIs, ou mais do que três em cada quatro ADIs catalogadas na base), sendo que a imensa maioria dessas ADIs foi proposta contra norma municipal, o percentual de vício formal (e, em especial, de vício de inciativa) deve ser mais acentuado do que o apresentado nas Tabelas 6 e 7 . Isto é previsível em virtude da distribuição conhecida dos dados classificáveis das ADIs contra normas municipais.
} 
Tabela 6 - ADI por Resultado e Vício de Inconstitucionalidade (TJs; 1990-2013)

\begin{tabular}{l|c|c|c|c|c|c|c|c}
\hline \multirow{2}{*}{ Resultado Julgamento } & \multicolumn{2}{|c|}{ Competência } & \multicolumn{2}{|c|}{ Iniciativa } & \multicolumn{2}{c|}{ Outra formal } & \multicolumn{2}{c}{ Material } \\
\cline { 2 - 9 } & $\mathbf{n}$ & $\boldsymbol{\%}$ & $\mathbf{n}$ & $\boldsymbol{\%}$ & $\mathbf{n}$ & $\boldsymbol{\%}$ & $\mathbf{n}$ & $\mathbf{\%}$ \\
\hline ADI Contra Requerente (total) & 282 & $23,9 \%$ & 939 & $12,1 \%$ & 182 & $30,1 \%$ & 1.053 & $27,6 \%$ \\
\hline ADI Pró-Requerente (total) & 896 & $76,1 \%$ & 6.848 & $87,9 \%$ & 423 & $69,9 \%$ & 2.768 & $72,4 \%$ \\
\hline
\end{tabular}

Fonte: Jurisprudência (TJ), base de dados organizada pelos autores [data missing $=5.805$ ].

Para finalizar a exposição da análise dos dados, é possível verificar que a quarta hipótese também é demonstrável empiricamente. Isto é, conforme postulado, o controle de constitucionalidade estadual protege as competências e prerrogativas do Executivo municipal, restringindo o poder do Legislativo. O principal demandante de ADIs é o Prefeito Municipal (cerca de $60 \%$ das ADIs com cerca de $72 \%$ de taxa de sucesso), que o faz quase que integralmente contra norma municipal $(98, \%)$ e em cerca de $60 \%$ dos casos invocando vício de iniciativa (ver Tabelas 7, 8 e 9). ${ }^{29}$ Ou seja, o tipo mais frequente de ADI que é julgada procedente em um TJ envolve um Prefeito Municipal requerendo a anulação de uma legislação aprovada por inciativa de membro da Câmara de Vereadores, arguindo para tanto a ocorrência de vício de iniciativa.

Tabela 7 - ADI por Requerente e Resultado (TJs; 1990-2013)

\begin{tabular}{l|cc|cc}
\hline \multirow{2}{*}{ Requerente } & \multicolumn{2}{|c|}{$\begin{array}{c}\text { ADI Contra } \\
\text { Requerente }\end{array}$} & \multicolumn{2}{c}{$\begin{array}{c}\text { ADI Pró- } \\
\text { Requerente }\end{array}$} \\
\cline { 2 - 6 } & $\mathbf{n}$ & $\mathbf{\%}$ & $\mathbf{n}$ & $\mathbf{\%}$ \\
\hline Prefeito/Município & 1.410 & $27,7 \%$ & 3.688 & $72,3 \%$ \\
\hline PGJ/MP & 904 & $29,0 \%$ & 2.217 & $71,0 \%$ \\
\hline Associação/Federação/Sindicato & 494 & $64,1 \%$ & 277 & $35,9 \%$ \\
\hline Partido & 292 & $67,0 \%$ & 144 & $33,0 \%$ \\
\hline Governador/Estado & 52 & $31,9 \%$ & 111 & $68,1 \%$ \\
\hline
\end{tabular}

\footnotetext{
${ }^{29}$ Como o data missing é o mais elevado na classificação do "requerente" (cerca de metade das vinte mil ADIs, variando um pouco em cada covariação das Tabelas 8, 9 e 10), resolvemos apresentar o item "sem classificação" nas referidas tabelas. Entretanto, provavelmente, os percentuais relativos aos "requerentes" ("prefeito", sobretudo, e em menor grau para o "PGJ") devem ser mais acentuados do que os possíveis de ser expressos nas tabelas para os itens classificáveis. Isto é previsível, dado que, entre os "requerentes sem classificação": 79,9\% obtém sucesso em sua demanda, que é em 93,7\% dirigida contra normas municipais, sendo que em $81,2 \%$ a alegação da ação envolve vício de inciativa. Em virtude disso, é provável que a maior parte dos requerentes não classificados sejam Prefeitos requerendo contra legislação aprovada por inciativa de membro da Câmara de Vereadores. Apesar da elevada quantidade de data missing, cremos que a apresentação dos dados sobre os "requerentes" permite compreender quais os tipos e resultados predominantes das ADIs julgadas pelos TJs.
} 


\begin{tabular}{l|cc|cc}
\hline Pessoa Física/Empresa & 126 & $100,0 \%$ & & $0,0 \%$ \\
\hline OAB & 30 & $57,7 \%$ & 22 & $42,3 \%$ \\
\hline [sem classificação] & 1.711 & $20,1 \%$ & 6.817 & $79,9 \%$ \\
\hline
\end{tabular}

Fonte: Jurisprudência (TJ), base de dados organizada pelos autores [data missing $=901$ ]

Tabela 8 - ADI por Requerente e Origem da Norma (TJs; 1990-2013)

\begin{tabular}{l|cc|cc}
\hline \multirow{2}{*}{ Requerente } & \multicolumn{2}{|c|}{ Estadual } & \multicolumn{2}{c}{ Municipal } \\
\cline { 2 - 5 } & n & \% & n & \% \\
\hline Prefeito/Município & 49 & $1,1 \%$ & 4.558 & $98,9 \%$ \\
\hline PGJ/MP & 212 & $6,9 \%$ & 2.860 & $93,1 \%$ \\
\hline Associação/Federação/Sindicato & 208 & $28,3 \%$ & 528 & $71,7 \%$ \\
\hline Partido & 26 & $6,5 \%$ & 373 & $93,5 \%$ \\
\hline Governador/Estado & 99 & $58,9 \%$ & 69 & $41,1 \%$ \\
\hline Pessoa Física/Empresa & 61 & $45,2 \%$ & 74 & $54,8 \%$ \\
\hline OAB & 20 & $40,8 \%$ & 29 & $59,2 \%$ \\
\hline [sem classificação] & 533 & $6,3 \%$ & 7.917 & $93,7 \%$ \\
\hline
\end{tabular}

Fonte: Jurisprudência (TJ), base de dados organizada pelos autores [data missing $=1.580$ ].

Tabela 9 - ADI por Requerentee Vício de Inconstitucionalidade (TJs; 1990-2013)

\begin{tabular}{l|c|c|c|c|c|c|c|c}
\hline \multirow{2}{*}{$\begin{array}{l}\text { Vício de } \\
\text { Inconstitucionalidade }\end{array}$} & \multicolumn{2}{|c|}{$\begin{array}{c}\text { Competência } \\
\text { Coniciativa }\end{array}$} & \multicolumn{2}{c|}{$\begin{array}{c}\text { Outra } \\
\text { formal }\end{array}$} & \multicolumn{2}{c}{ Material } \\
\cline { 2 - 12 } & $\mathbf{n}$ & $\mathbf{\%}$ & $\mathbf{n}$ & $\mathbf{\%}$ & $\mathbf{n}$ & $\mathbf{\%}$ & $\mathbf{n}$ & $\mathbf{\%}$ \\
\hline Prefeito/Município & 458 & $12,7 \%$ & 2096 & $58,2 \%$ & 125 & $3,5 \%$ & 923 & $25,6 \%$ \\
\hline PGJ/MP & 165 & $6,8 \%$ & 271 & $11,1 \%$ & 112 & $4,6 \%$ & 1886 & $77,5 \%$ \\
\hline Associação/Federação/Sindicato & 127 & $25,7 \%$ & 107 & $21,6 \%$ & 24 & $4,8 \%$ & 237 & $47,9 \%$ \\
\hline Partido & 24 & $8,4 \%$ & 30 & $10,5 \%$ & 25 & $8,7 \%$ & 208 & $72,5 \%$ \\
\hline Governador/Estado & 24 & $21,4 \%$ & 47 & $42,0 \%$ & 1 & $0,9 \%$ & 40 & $35,7 \%$ \\
\hline Pessoa Física/Empresa & 6 & $16,7 \%$ & 7 & $19,4 \%$ & 4 & $11,1 \%$ & 19 & $52,8 \%$ \\
\hline OAB & 2 & $9,5 \%$ & 1 & $4,8 \%$ & & $0,0 \%$ & 18 & $85,7 \%$ \\
\hline [sem classificação] & 387 & $6,0 \%$ & 5270 & $81,2 \%$ & 320 & $4,9 \%$ & 515 & $7,9 \%$ \\
\hline
\end{tabular}

Fonte: Jurisprudência (TJ), base de dados organizada pelos autores [data missing $=5.717]$.

\section{CONCLUSÃO}

Há a necessidade de aprofundar o levantamento de dados nos TJs e refinar o tratamento dos dados e a classificação dos indicadores construídos. Contudo, os dados apresentados corroboram empiricamente e apontam para a validade explanatória das hipóteses 
extraídas da literatura sobre o papel centralizador do controle de constitucionalidade na federação brasileira.

Relembrando as afirmações que foram propostas como hipóteses de trabalho e confirmadas pela análise neste artigo: (H1) os TJs são relevantes atores políticos no processo de tomada de decisão política, declarando inconstitucionais atos normativos estaduais e municipais e ampliando a centralização federativa brasileira em razão da extensão do texto das Constituições Estaduais e das restrições à revisão dessas decisões pelo STF; $(\mathrm{H} 2)$ o controle de constitucionalidade é mais forte em relação aos atos normativos municipais do que sobre os atos estaduais, pois o órgão julgador do Tribunal de Justiça possui menor relação institucional com os órgãos e as autoridades que produzem normas municipais e o papel de controle federativo dos atos normativos estaduais, sobretudo legislação, foi delegada constitucionalmente ao STF; (H3) os fundamentos para declaração de inconstitucionalidade dos atos normativos encontram-se preferencialmente em vícios formais (iniciativa e competência) e não em questões materiais; (H4) o controle de constitucionalidade estadual protege as competências e prerrogativas do Executivo municipal, restringindo o poder legislativo local. Ou, dito de outra forma e mais resumida, dada a distribuição de competências federativas centralizados e as prerrogativas do chefe do executivo municipal, o tipo mais frequente de ADI que é julgada procedente em um TJ envolve um Prefeito Municipal requerendo a anulação de uma legislação aprovada por inciativa de membro da Câmara de Vereadores, arguindo para tanto a ocorrência de vício de iniciativa.

Essa conclusão segue a de estudos anteriores que indicam que o controle de constitucionalidade exercido pelo STF e pelos TJs (via ADI) tem um papel concentrador nas relações federativas, validando a proposição de Bzedera (1993) que, basicamente, sustenta que o controle abstrato de constitucionalidade tem como objetivo restringir a federação/descentralização a partir de prerrogativas consolidadas constitucionalmente pelo poder central.

O arranjo institucional e a distribuição de competências entre os níveis de governo passam a serem fatores explicativos centrais sobre as decisões que envolvem o controle federativo/descentralização na judicialização da política. Ou seja, as determinações constitucionais do arranjo federativo/relações intergovernamentais (plenamente identificáveis na alegação de vícios formais: de inciativa e de competência legislativa) aumentam a probabilidade dos tribunais constitucionais, como o STF e, no caso central desse estudo, os 
Tribunais de Justiça, promoverem a centralização política, na medida em que limitam as iniciativas legislativas descentralizadoras dos governos locais/unidades federadas (o típico em federações centralizadas) e as iniciativas legislativas dos parlamentos estaduais e municipais (o que parece ser mais específico à federação brasileira).

\section{REFERÊNCIAS}

ALIVIZATOS, Nicos. Judges as veto players. In.: DÖRING, H. (org.).Parliaments and majority rule in Western Europe.Frankfurt: Campus, 1995.

BZDERA, A. Comparative Analysis of Federal High Courts: A Political Theory of Judicial Review. Canadian Journal of Political Science, XXVI:1, march 1993.

CANOTILHO, J. J. G. Direito Constitucional e Teoria da Constituição.7. ed. Coimbra: Almedina, 2003.

CARVALHO, E. R. Judicialização da política no Brasil: controlo de constitucionalidade e racionalidade política. Análise Social, Lisboa, n. 191, abr. 2009.

CONJUR. $83 \%$ das normas submetidas à Justiça de SP são inconstitucionais. Boletim de Notícias Conjur. 29 de dezembro de 2014, 15h02. Disponível em: http://www.conjur.com.br/2014-dez-29/83-normas-submetidas-justica-sp-saoinconstitucionais. Acesso em 05/01/2015.

CLÈVE, C. M. Controle de Constitucionalidade e Democracia. In: MAUÉS, A. G. M. Constituição e Democracia. São Paulo: Max Limonad, 2001, p. 49-60.

DWORKIN, R. $O$ direito da Liberdade: a Leitura Moral da Constituição. São Paulo: Martins Fontes, 2006.

EMMERT, C. F. An Integrated Case-Related Model of Judicial Decision Making: Explaining State Supreme Court Decisions in Judicial Review Cases. The Journal of Politics, v. 54, n. 2, p. 543-555, May, 1992.

FIGUEROA, J. R. \& TAYLOR, M. M. Institutional Determinants of the Judicialisation of Policy in Brazil and Mexico. Journal Latin American Studies, 38, 2006, p. 739-66.

FREITAG, M., VATTER, A. Patternsofdemocracy: A subnationalanalysisoftheGermanLänder. Acta Politica, v. 44, 4, p. 410-438, 2009.

GARGARELlA, R. El Derecho Frente a la Protesta Social. In: __ Teoría y Crítica delDerecho Constitucional. Buenos Aires: Abeledo-Perrot, 2008, p. 821-838.

GARZA, J. M. S. Strengtheningstateconstitutionalismfromthe federal Constitution: the case ofMexico. World CongressofConstitutional Law 2014, Oslo Workshop 2, SubnationalConstitutions in Federal andQuasi-Federal ConstitutionalStates. 2014.

HAMILTON, A., MADISON, J. e JAY, J. O Federalista. Campinas: Russell, 2009.

LEVINSON, Sanford. State constitutions as artifacts of experimentations. Rutgers law journal. v. 44, 2014, p. 579-598.

MARRAFON, M. A. Federalismo brasileiro: reflexões em torno da dinâmica entre autonomia e centralização. In: CLÈVE, C. M. Direito Constitucional Brasileiro. Volume II. São Paulo: Revista dos Tribunais, 2014, p. 95-120.

MEIRELLES, Hely Lopes. Direito Municipal, 14ª ed. São Paulo: Malheiros, 2006.

MENDES, C. H. Controle de Constitucionalidade e Democracia. Rio de Janeiro: Elsevier, 2008 . 
MENDES, G. F. Jurisdição Constitucional. São Paulo: Saraiva, 2014.

PONTES DE MIRANDA. Comentários à Constituição de 1967 com a Emenda $n .1$ de 1969. Tomo II.

TARLTON, Charles D. Symmetry and Asymmetry as Elements of Federalism: A Theoretical Speculation. The Journal of Politics 27, $\mathrm{n}^{\circ} .4$, p. 861-874, nov. 1965.

TARR, Alan. State Constitutions and State Political History. The Journal of American History, v. 81, n . 4, p. 1863-1867, mar. 1995.

TAYLOR, M. M.; DA ROS, L. Os partidos dentro e fora do poder: a judicialização como resultado contingente da estratégia política. Dados, v. 51, n. 4, 2008.

TOMIO, F. R. L. Iniciativas, cenários e decisões no processo legislativo estadual. Revista Estudos Legislativos, n. 5, 2012.

TOMIO, F. R. L., ORTOLAN, M., CAMARGO, F. S. Análise Comparativa dos Modelos de Repartição de Competências Legislativas nos Estados Federados. Revista da Faculdade de Direito. Universidade Federal do Paraná, v. 51, p. 73-100, 2010.

Autonomia dos governos locais em federações: uma análise comparativa. Revista

Brasileira de Estudos Constitucionais, Belo Horizonte, v. 5, n. 19, p. 53-92, jul./set. 2011.

TOMIO, F. R. L., RICCI, Paolo. Seis décadas de processo legislativo estadual: processo decisório e relações executivo/legislativo nos estados (1951-2010). Cadernos da Escola do Legislativo, v. 13, p. 57-108, 2012a.

O governo estadual na experiência política brasileira: os desempenhos legislativos das assembléias estaduais. Revista de Sociologia e Politica, Curitiba, v. 20, n. 41, 2012b.

TOMIO, F. R. L., ROBL FILHO, I. N. Empirical Legal Research: Teoria e Metodologia para uma Abordagem do Processo Decisório de Controle de Constitucionalidade no STF. In: SIQUEIRA, G. S., VESTENA, C. A. Volume II. Belo Horizonte: Arraes, 2013, p. 96-117.

TSEBELIS, George. Poder Judiciário e burocracias. In.: TSEBELIS, G. Atores com Poder de Veto. Rio de Janeiro: EdFGV, 2009.

VANBERG, G. Abstract judicial review, legislative bargaining, and policy compromise.Journal of Theoretical Politics, 10 (3), 1998, p. 299-327.

VANBERG, G. Legislative-Judicial Relations: A Game-Theoretic Approach to Constitutional Review. American Journal of Political Science, Vol. 45, No. 2, April 2001, p. 346-361.

VIANNA, L. W.; BURGOS, M. B.; SALLES, P. M. Dezessete anos de judicialização da política. Tempo Social, v. 19, n. 2, Nov. 2007.

WATTS, Ronald T., Asymmetrical Decentralization: Functional or Dysfunctional. Paper Presented at International Political Science Association. Québec City, Québec, Canada, August 2000. Disponível em: http://www.forumfed.org/libdocs/AsymFed00/915ASFE0008-int-Ron-Watts.htm. Acesso em 15/12/2014.

WILLIANS, Robert F., Teaching and Researching Comparative Subnational Constitutional Law. Penn State Law Review, vol. 115, no 4, p. 1109-1131, 2011. 